\title{
Research Paper: The Effectiveness of Motor Therapy on Motor Skills and Bilateral Coordination of Children With Intellectual Disability
}

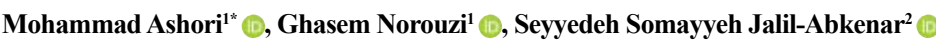

1. Department of Psychology and Education of Children with Special Needs, Faculty of Education and Psychology, University of Isfahan, Isfahan, Iran 2. Department of Psychology and Education of Exceptional Children, Faculty of Psychology and Education, University of Tehran, Tehran, Iran.

\begin{tabular}{l|l}
$\begin{array}{c}\text { use vour devict os san } \\
\text { and read the article online }\end{array}$ \\
$\begin{array}{l}\text { Cftation Ashori M, Norouzi Gh, Jalil-Abkenar SS. The Effectiveness of Motor Therapy on Motor Skills and Bilateral Coordination } \\
\text { of Children With Intellectual Disability. Iranian Rehabilitation Journal. 2018; 16(4):331-338. http://dx.doi.org/10.32598/irj.16.4.331 }\end{array}$ \\
doi http://dx.doi.org/10.32598/irj.16.4.331
\end{tabular}

Article info:

Received: 10 Jan 2018

Accepted: 25 May 2018

Available Online: 01 Dec 2018

Keywords:

Motor, Motor skills, Intellectual disability

\section{ABSTRACT}

Objectives: Motor therapy plays a key role on the bilateral coordination skills and motor activities of children with Intellectual Disability (ID). The present research aimed to investigate the effectiveness of motor therapy on motor skills and bilateral coordination skills of students with ID.

Methods: This was a quasi-experimental research with pre-test and post-test and control group design. The study participants were 26 male students with ID from 2 special schools in Tehran City, Iran. The samples were selected by cluster sampling method. They were randomly divided into the experimental and control groups and each group consisted of 13 students. In the experimental group, motor therapy was performed during 16 sessions, while the control group did not receive any trainings. Bruininks-Oseretsky Test of motor proficiency was used for measuring gross motor skills, fine motor skills and bilateral coordination skills of the students. The obtained data were analyzed using Multivariate Analysis of Covariance (MANCOVA).

Results: MANCOVA results indicated a significant difference between the gross motor skills, fine motor skills and bilateral coordination skills in the experimental group, following the intervention $(\mathrm{P}<0.0001)$.

Discussion: Motor therapy improved motor skills and bilateral coordination skills of students with ID. Therefore, taking motor therapy could have positive impacts on the motor skills and bilateral coordination skills of students with ID. 


\section{Highlights}

- Motor therapy has positive effects on motor skills and bilateral coordination of students with intellectual disabilities.

- There are significant differences between control and experimental (students with intellectual disability with training) groups with regard to the scores of motor skills and bilateral coordination.

- The changes of scores are due to the effect of motor therapy training on the experimental group.

\section{Plain Language Summary}

Children with intellectual disability are among the largest group of the children with special needs. Limitation in motor skills and bilateral coordination is a common characteristic of these children. These skills are very important for individual care activities and daily living skills, too. The motor therapy is defined as training of the basic motor skills that have significant influence on the development of more complex skills and recreational physical skills. The present research was conducted on 26 male students with intellectual disabilities from two special schools in Tehran to examine the effect of motor therapy program on them. The experimental group participated in 16 intervention sessions and trained by motor therapy program, while control group did not. Motor therapy training led to the improvement of motor skills and bilateral coordination of students with intellectual disabilities.

\section{Introduction}

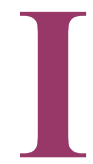

ntellectual Disability (ID) refers to considerable problems in intellectual functioning and adaptive behavior. This disorder is developed before the age of 18 [1-3] Students with ID have deficits in cognitive development and lack skills in various domains such as friendship [4], emotions [5], cognition, psychosocial status, language and activities [6]. Limited motor skills is an ever-present condition in these students, because ID is a condition of deficiency in brain functions, which affects the cognition as well as motor skills $[7,8]$.

Motor skill development includes gross motor skills, fine motor skills and bilateral coordination skills. Gross motor skills refer to large muscle movements, such as jumping, walking, climbing up and down, catching and throwing, coordination between hands and feet. Fine motor skills refer to how a child controls things and uses arms and hands. Bilateral coordination refers to how a child handles body coordination in activities, such as jumping up and around, finger-tapping, and toe-tapping movements. These skills are very important in self-care activities and daily living skills. Children with ID have many physical problems that influence their motor skills. For example, such children need help with the gross motor activities like vacuuming and sweeping or with fine motor activities like zip up/unzip or a button/unbutton [9].
For many years, it has been believed that individuals with ID could not learn and live in seclusion [10]. Currently, social attitudes have changed and it is recognized that individuals with ID can learn if taught appropriately [1]. In addition, intellectually disabled students frequently have problems in motor activities [11] which are constantly reported by parents and professionals $[12,13]$.

Motor therapy is defined as training the basic motor skills that significantly influence the development of the more complex skills such as playing games, active playing, dancing, performing sports activities, gymnastics, and recreational physical skills [14]. The principles of motor therapy were derived from contemporary neuroscience, occupational therapy, and developmental psychology [15]. Motor therapies are progressively applied by therapists for managing the children with intellectual disabilities. These therapies encourage skills and activities that are thought to handle the sensory neural system by providing proprioceptive, vestibular, tactile and auditory inputs. Balls, swings, brushes, and other particularly intended or recreational therapeutic equipment are used for reinforcing these inputs [9].

Evidence demonstrates that the motor skills of students with ID are considerably poor and delayed [16]. A research investigated the effect of Spark exercise program on improving manipulative skills of students with developmental coordination disorder. The results demonstrated that Spark exercise program significantly improved manipulative skills in the experimental group, compared 
to the control group [17]. Another study investigated the effect of fundamental movement skills program on improving the adaptive behavior, social skills and motor skills of 4-year-old children with autism spectrum disorders. Their results indicated that the motor skills significantly improved in the experimental group. In addition, there were no considerable changes in adaptive behavior and social skills [18].

Another research assessed the effectiveness of Spark program on the improvement of gross motor skills in children with ID. Their findings indicated that this program can improve gross motor skills in students with ID [19]. Another research investigated the effects of teaching basic motor skills to 6 -year-old boys and girls. The results indicated that motor therapy improved gross and fine motor skills in children with ID [20].

A study investigated the effectiveness of perceptual motor activities on auditory and visual attention of children with Attention-Deficit/Hyperactivity Disorder (ADHD). Their results demonstrated a significant improvement in visual and auditory attention performance in the experimental group [21]. A study examined the effect of sensory-motor interventions on the attention span of students with learning disabilities. Results indicated that sensory-motor interventions increased the attention span of these students [22].

Another study investigated the effectiveness of creative movements on the attention span of students with autism spectrum disorders. Their results presented a significant improvement in the attention span of the experimental group [23]. Another research investigated the effectiveness of improving gross motor activities on the attention processing of students with Down Syndrome. Results of their study indicated that improved gross motor activities increased the attention processing of the subjects [24].

According to some studies, students with ID show delays in the motor skills development [8, 25-27]. Moreover, the results of some studies demonstrate that the rates of cognitive and motor activities are related with each other in students with ID $[8,27]$. Children with ID have problems in sensory integration which negatively affects their gross and fine motor skills. In addition, studies reveal that children with ID have low levels of motor skills in comparison with normal children.

Considering this, motor therapy is very beneficial for them. Motor skills and daily activities improved in students with ID, after attending a motor skills program. In addition, students with ID process similar steps of mo- tor functions and develop in the same order as normal students. However, stages may be obtained later and may not be developed for some activities and skills [16]. Therefore, this research aimed to determine the effectiveness of motor therapy on motor skills and bilateral coordination of students with ID.

\section{Methods}

This was a quasi-experimental research with pre-test, post-test and a control group design. The study participants were 18 elementary school students with ID from Tehran City, Iran. The subjects were selected by cluster sampling method. Out of all elementary schools, 2 schools were randomly selected. The students were randomly divided into the experimental and control groups and each group consisted of 13 children. We required 12 subjects for the experimental and control groups, based on the mean of the subjects in 3 recent research studies in this area. Sample size was calculated equal to 13 , by the following formula:

$$
n=\frac{\sigma^{2}\left(z_{1}-a / 2\right)^{2}}{d^{2}}=(22.07)^{2} \times(1.96)^{2} /(12)^{2}=13
$$

The inclusion criteria were being diagnosed with mild ID, living with parents, being between 8 and 10 years old and studying at second to fourth graders. The subjects would be excluded from the research if they had any symptoms of neurodevelopmental disability or significant health problems. Also, those who were currently receiving similar training programs were excluded from the research. The importance of this study was described for the mothers of subjects and school counselors. The subjects' mothers provided their informed consent. Then, the experimental group participated in 16 motor therapy sessions and the control group participated in the routine program of school.

To evaluate the motor skills and bilateral coordination, Bruininks-Oseretsky Test of motor proficiency-short form (BOT-2) was used. This is well-known test for assessing motor proficiency. It was designed to obtain useful information about the motor skills of children aged 4.5 to 14.5 years. BOT-2 included 14 items and 8 subscales [28]. In this study, 3 subscales of BOT-2 were used to evaluate fine motor skills. The applied subscales included fine motor integration, fine motor precision, and manual dexterity. Four subscales were used to assess gross motor skills, including balance, speed and agility, upper-limb coordination, and strength. Also, bilateral coordination subscale was used to evaluate both gross motor skills and fine motor skills. The test-retest reliability coefficient of BOT-2 is reported to be 0.86 [29]. 
Table 1. The content of motor therapy program sessions

\begin{tabular}{|c|c|c|}
\hline Session & Objects & Context of Sessions \\
\hline 1 & Identification of child situation & Physical exercises, individual and group activities \\
\hline 2 & Coordination of gross motor & $\begin{array}{c}\text { Activities such as sit down/stand up, bending and straightening the body } \\
\text { hands movement }\end{array}$ \\
\hline 3 & Reinforcement of gross muscles & $\begin{array}{l}\text { Drawing, pushing and moving utensils with and without a wheel in direct } \\
\text { and indirect paths }\end{array}$ \\
\hline 4 & Reinforcement of body harmony and stability & Walking on a direct line, jumping in rings, jumping in color circles \\
\hline 5 & Reinforcement of static and dynamic balance & $\begin{array}{l}\text { Single-leg stand up on toes and heel of foot, moving back and forth, single- } \\
\text { leg and both leg jump }\end{array}$ \\
\hline 6 & Reinforcement of attention and motor skills & $\begin{array}{c}\text { Single-leg stand up at various times, ball throw in various paths, ball pass } \\
\text { between trainer legs }\end{array}$ \\
\hline 7 & Reinforcement of hand and trunk muscles & $\begin{array}{l}\text { Concurrent moving of hands and trunk in various paths, hand walking while } \\
\text { trainer holds the legs }\end{array}$ \\
\hline 8 & $\begin{array}{l}\text { Increasing attention span and eye and } \\
\text { hand coordination }\end{array}$ & $\begin{array}{c}\text { Activities such as wear attaching clothes, throw coins into till, screwing and } \\
\text { unscrewing bolts and conducting same activities }\end{array}$ \\
\hline 9 & $\begin{array}{l}\text { Reinforcement of tactile sensory and body } \\
\text { awareness }\end{array}$ & $\begin{array}{l}\text { Activities such as playing with clay and paste, finding things, hiding things in } \\
\text { grit and sand, rolling on grit and sand }\end{array}$ \\
\hline 10 & Coordination of fine and complex skills & $\begin{array}{l}\text { Activities such as ball rolling on ground and passing through obstacles, sorting } \\
\text { play, play with passel and logo }\end{array}$ \\
\hline 11 & Reinforcement of body balance and stability & $\begin{array}{c}\text { Walking and running in various positions through paths such as line path or } \\
\text { lining placement and jumping over obstacles }\end{array}$ \\
\hline 12 & Coordination of complex motor & Activities with cage, legs, hand and arm muscles such as aerobic movements \\
\hline 13 & $\begin{array}{l}\text { Reinforcement of orientation and active } \\
\text { motor coordination }\end{array}$ & $\begin{array}{l}\text { Twosome races in activities such as catching a ball without falling, fast } \\
\text { movements for reaching the ball }\end{array}$ \\
\hline 14 & $\begin{array}{l}\text { Concurrent reinforcement of attention } \\
\text { span and dynamic balance }\end{array}$ & $\begin{array}{l}\text { Holding water glass on palm in standing and movement positions, carrying } \\
\text { several water glasses with platter }\end{array}$ \\
\hline 15 & $\begin{array}{l}\text { Increasing eye and hand coordination and } \\
\text { aiming }\end{array}$ & $\begin{array}{l}\text { Use utensil such as bubble making, throwing up bladder and hit with hand } \\
\text { to under it, throwing ball into quadrille on wall }\end{array}$ \\
\hline 16 & $\begin{array}{l}\text { Reinforcement of orientation and selective } \\
\text { attention }\end{array}$ & $\begin{array}{l}\text { Hitting balls with a club, tracing colored lights in a dark room, tracing hang- } \\
\text { ing colored balls and hitting those with certain regularity }\end{array}$ \\
\hline
\end{tabular}

IIranian Rehabilitation Journa

The motor therapy program was used in the present research. The experimental group received motor therapy in 16 sessions (3 times a week; 45 minutes each), while control group did not receive such program. Motor therapy program was designed based on Spark motor program [29]. This program has been applied in several research studies $[19,22,24]$. The content of motor therapy sessions were as follows (Table 1).

To assess motor skills and its subscales (gross motor skills, fine motor skills and bilateral coordination skills) in students with ID, BOT-2 was used as the pre-test. Then, the experimental group participated in 16 intervention sessions. In the final stage of the research, each of the 2 groups were assessed by BOT- 2 as the post-test. The obtained data were analyzed by Multivariate Analysis of Variance (MANOVA) using SPSS.

\section{Results}

The mean age of experimental and control groups were 8.71 and 8.73 years and their mean IQ scores were 61.35 and 62.02, respectively. A comparison was made using descriptive statistics with respect to each group's scores on the motor skills and gross motor skills, fine motor skills and bilateral coordination skills subscales. Mean \pm SD scores for each group were considered as overall group indexes (Table 2).

Multivariate Analysis of Covariance (MANCOVA) was used because of the presence of an independent variable and several dependent variables and adjusting pre-test effect. After checking and confirmation of the normality of research variables, Box's test approved the equality of variance-covariance matrices $(\mathrm{P}>0.05)$. In addition, the assumption of variance equality was approved using Levene's Test ( $\mathrm{P}>0.05)$. Therefore, MAN- 
Table 2. Descriptive statistics for motor skills and subscales in study groups

\begin{tabular}{cccccc}
\hline \multirow{2}{*}{ Subscales } & Stage & \multicolumn{2}{c}{ Experimental } & \multicolumn{2}{c}{ Control } \\
\cline { 3 - 6 } & & Mean & SD & Mean & SD \\
\hline \multirow{2}{*}{ Gross motor skills } & Pre-test & 34.51 & 5.15 & 33.65 & 4.85 \\
& Post-test & 44.89 & 5.65 & 34.84 & 5.80 \\
Fine motor skills & Pre-test & 29.62 & 3.72 & 29.25 & 3.25 \\
Bilateral coordination & Post-test & 39.47 & 3.15 & 29.65 & 3.42 \\
skills & Pre-test & 8.05 & 2.78 & 8.23 & 2.65 \\
Total motor skills & Post-test & 12.35 & 2.31 & 8.85 & 2.87 \\
\hline
\end{tabular}

Iranian Rehabilitation Đournal

COVA could be applied. The overall score of Wilk's lambda was significant, $\left(\mathrm{F}_{4,17}=4.02, \mathrm{P}=0.0001\right)$, indicating that the experimental and control groups had a significant difference, at least in one variable. In order to determine differences among the scores of motor skills and subscales (gross and fine motor skills and bilateral coordination skills) between the control and experimental groups, MANCOVA was used, which the results are presented in Table 3.

To analyze the obtained data, pre-test variable was moderated because of its correlation with post-test. According to Table 3, the type of the group affects posttest scores significantly, and there are significant differences among the scores of motor skills and gross motor skills, fine motor skills, and bilateral coordination skills subscales, between the experimental and control groups $(\mathrm{P}<0.0001)$. As per Table 3 , the results of MANCOVA indicated that motor therapy had a positive and significant effect on the gross motor skills $(\mathrm{F}=30.84$, $\mathrm{P}<0.0001$ ), fine motor skills ( $\mathrm{F}=33.01, \mathrm{P}<0.0001)$, bilateral coordination skills $(\mathrm{F}=24.35, \mathrm{P}<0.0001)$ and motor skills ( $\mathrm{F}=29.12, \mathrm{P}<0.0001)$. According to eta square $\left(\eta^{2}\right)$, this could be explained that $60 \%, 57 \%, 51 \%$ and $54 \%$ of the variation in each variable of gross and fine motor skills, bilateral coordination skills and motor skills, respectively, are due to the effectiveness of motor therapy in the experimental group.

Table 3. Summary of MANCOVA results

\begin{tabular}{ccccccccc}
\hline Source & Dependent Variable & SS & df & MS & F & Sig. & $\mathbf{\eta}^{2}$ \\
\hline & Gross motor skills & 25.58 & 1 & 25.58 & 7.93 & $<0.001$ & 0.170 \\
Pre-test & Fine motor skills & 27.65 & 1 & 27.65 & 10.70 & $<0.0005$ & 0.210 \\
& Bilateral coordination & 18.07 & 1 & 18.07 & 4.38 & $<0.05$ & 0.140 \\
& Motor skills & 24.51 & 1 & 24.51 & 6.54 & $<0.001$ & 0.170 \\
& Gross motor skills & 197.27 & 1 & 197.27 & 30.84 & $<0.0001$ & 0.600 \\
Group & Fine motor skills & 167.55 & 1 & 167.55 & 33.01 & $<0.0001$ & 0.570 \\
& Bilateral coordination & 89.98 & 1 & 89.98 & 24.35 & $<0.0001$ & 0.510 \\
& Motor skills & 160.11 & 1 & 160.11 & 29.12 & $<0.0001$ & 0.54 \\
\hline
\end{tabular}




\section{Discussion}

This study was conducted to investigate the effect of motor therapy on motor skills of children with ID. In addition, the present research evaluated the effectiveness of motor therapy on bilateral coordination skills of students with ID in the two groups (experimental and control) before and after the intervention.

The present study supports the effectiveness of motor therapy on gross and fine motor skills, bilateral coordination skills and total motor skills of students with ID. The results of this research were consistent with Sadati Firoozabadi and Abasi, stating the effect of sensory motor integration training program on the motor skills in children with learning disorders [30]. The obtained results were in line with Amel and Amira study which investigated the effect of sensory integration training program on motor skills in students with autism spectrum disorders [9]. They reported a statistically significant difference between the experimental and control groups in gross and fine motor skills after intervention. Current study results were consistent with the findings of Shahbazi, Rahmani, and Heyrani, representing the effectiveness of sensory motor integration program on reaction time and balance in students with developmental coordination disorder [31].

Results of the current research were in line with the study of Top, that investigated the effects of swimming exercises program on the motor development levels in teenagers with ID and stated a statistically significant difference between the experimental and control groups in fine motor integration, fine motor precision, and bilateral coordination skills [8]. Moreover, Top concluded that there were no differences in the experimental and control groups in gross motor skills and total motor skills at pre-test and post-test. This part of their results were inconsistent with the present study [8]. Moreover, the present research results were consistent with the results of Parhoon, Parhoon, and Movallali. They investigated the effect of sensory motor program on gross motor skills among students with Down syndrome aged 5-7 years. They reported a statistically significant difference between the control and experimental groups, in gross motor skills after intervention [32].

The findings of this research were in line with the study by Westendorp, Houwen, Hartman and Visscher [6]. They reported that in children with mild ID, the scores of the gross motor skills of the experimental group in sports were significantly higher than that of the control group. Furthermore, the present study was consistent with the results of Vuijk, Hartman, Scherder and Visscher [27]. They concluded that motor performance in students with borderline intellectual functioning and mild ID increased after intervention. Present study results were consistent with the findings of Surtchi, Sazande, Nori, and Jadidi, stating the effectiveness of sensory integration program on fine and gross motor skills, for 5- to 7-year-old children with Down syndrome [33]. Moreover, this result was similar with the study of Bouffard [26]. They concluded that there was a significant difference in the motor skills of individuals with educable ID after intervention.

To explain these finding, it can be stated that motor therapy included training the basic motor skills that significantly influence the later development of higher level activities [14]. Motor therapy is used for managing motor skills in students with ID [9]. Thus, it is expected that motor therapy improves motor skills and bilateral coordination skills. To clarify, at birth, the actions and movements of a child depend on input from sensory channels. When child grows up and his or her interaction with environment improves, the visual and auditory system become very important and are accompanied by other sensory systems. Hand and eye coordination requires provision of many sensory inputs for direct movements towards the target. When a baby' hand contacts the target, baby integrates tactile information regarding object's texture via visual proprioceptive about size, color and shape.

More contact with the object, assemble information feedback from baby's hand movements in respond to the object, which may help to explain data regarding the shape and size of that object [34]. Also, appropriate operation tasks are used for students with sensory processing problems to help decrease defensiveness, as well as improve their arousal and attention. Increased fine and gross motor skills in students will allow them to perform various considerable operation activities [9]. In addition, motor therapy plays a key role on the motor skills and bilateral coordination skills of children. Although a few children with ID obtain appropriate motor activities through observation and imitation of classmates and other children in classroom and community, it is important that parents and teachers engage these children in acquiring of motor skills, directly and indirectly. As a result of this improvement in motor skills, it can be assumed that motor therapy program can have positive and significant effects [16].

Motor skills training increase the neuroplasticity of nervous system in children, leading to improvements in desirable skills and behaviors and learning capacity. 
Furthermore, motor therapy programs emphasize on proprioceptive, tactile, and vestibular system. Accordingly, it improves spontaneous reaction, muscle tone and emotion regulation [9].

\section{Conclusion}

It is expected that motor therapy improves motor skills and bilateral coordination skills. Motor therapy also facilitates the improvement of motor skills and bilateral coordination skills in students with ID. Thus, paying attention to motor therapy plays a crucial role for enhancing motor skills and bilateral coordination skills in students with ID. Ultimately, the present research demonstrated that significant improvement in motor skills and bilateral coordination skills of students with ID were reinforced after receiving motor therapy intervention.

Several limitations of the current research should be noted. The rate of learning differs in students with ID. It is difficult to ascertain the achievement of these students in motor skills. Moreover, we disregarded the socioeconomic status of students' parents. Therefore, cautious should be taken in the generalization of these research findings to other students. In addition, the sample size was small. Because each group consisted of 13 students, it is difficult to relate these results to other children with special needs. Moreover, because of the time limitation, opportunity for a follow-up stage was not provided.

\section{Ethical Considerations}

\section{Compliance with ethical guidelines}

This research was approved by the Human Ethics Research Committee of Isfahan University and the Exceptional Education Organization of Iran.

\section{Funding}

This research did not receive any specific grant from funding agencies in the public, commercial, or not-for-profit sectors.

\section{Authors contributions}

The authors contributions is as follows: Conceptualization: All authors; Methodology: Mohammad Ashori and Seyyedeh Somayyeh Jalil-Abkenar; Investigation: Mohammad Ashori and Ghasem Norouzi; Writing-Original Draft: All authors; Writing-Review \& Editing: Mohammad Ashori; Resources: All authors; and Supervision: Mohammad Ashori and Ghasem Norouzi.

\section{Conflict of interest}

The authors declared no conflict of interest.

\section{Acknowledgements}

We would like to acknowledge the support of the Special Educational Needs Organization and special schools staff in Tehran for their sincere cooperation whose support made conducting this research possible.

\section{References}

[1] Adibsereshki N, Abkenar SJ, Ashoori M, Mirzamani M. The effectiveness of using reinforcements in the classroom on the academic achievement of students with intellectual disabilities. Journal of Intellectual Disabilities. 2015; 19(1):83-93 [DOI:10.1177/1744629514559313] [PMID]

[2] Ashori M, Jalil Abkenr SS. [Students with special needs and inclusive education. (Persian)]. Tehran: Roshd-e Farhang; 2006.

[3] Kirk S, Gallagher JJ, Coleman MR, Anastasiow NJ. Educating exceptional children (What's new in education). Belmont Wadsworth Publishing Group; 2011.

[4] Bigby C, Craig D. A case study of an intentional friendship between a volunteer and adult with severe intellectual disability: "My life is a lot richer!". Journal of Intellectual \& Developmental Disability. 2017; 42(2):180-9. [DOI:10.3109/13668 250.2016.1219701]

[5] Santomauro D, Sheffield J, Sofronoff K. Investigations into emotion regulation difficulties among adolescents and young adults with autism spectrum disorder: A qualitative study. Journal of Intellectual \& Developmental Disability. 2017; 42(3):275-84. [DOI:10.3109/13668250.2016.1236240]

[6] Westendorp M, Houwen S, Hartman E, Visscher C. Are gross motor skills and sports participation related in children with intellectual disabilities. Research in Developmental Disabilities. 2011; 32(3):1147-53. [DOI:10.1016/j.ridd.2011.01.009] [PMID]

[7] Giagazoglou P, Arabatzi F, Dipla K, Liga M, Kellis E. Effect of a hippotherapy intervention program on static balance and strength in adolescents with intellectual disabilities. Research in Developmental Disabilities. 2012; 33(6):2265-70. [DOI:10.1016/j.ridd.2012.07.004] [PMID]

[8] Top E. The effect of swimming exercise on motor development level in adolescents with intellectual disabilities. American Journal of Sports Science and Medicine. 2015; 3(5):85-9. [DOI:10.12691/ajssm-3-5-1]

[9] Amel E, Amira H. Effectiveness s of sensory integration program in motor skills in children with autism. The Egyp tian Journal of Medical Human Genetics. 2015; 16(4):375-80. [DOI:10.1016/j.ejmhg.2014.12.008]

[10] Johnson H, Bigby C, Iacono T, Douglas J, Katthagen S, Bould E. Increasing day service staff capacity to facilitate positive relationships with people with severe intellectual disability: Evaluation of a new intervention using multiple baseline 
design. Journal of Intellectual \& Developmental Disability. 2017; 42(4):391-02. [DOI:10.3109/13668250.2016.1246656]

[11] Tolmie J. Fragile $X$ syndrome - diagnosis, treatment and research. Journal of Medical Genetics. 2002; 39(10):782-3. [DOI:10.1136/jmg.39.10.783] [PMCID]

[12] Hessl D, Berry Kravis E, Cordeiro L, Yuhas J, Ornitz EM, Campbell A, et al. Prepulse inhibition in fragile X syndrome: Feasibility, reliability, and implications for treatment American Journal of Medical Genetics. 2009; 150B(4):545-53. [DOI:10.1002/ajmg.b.30858]

[13] Yuhas J, Cordeiro L, Tassone F, Ballinger E, Schneider A, Long JM, et al. Brief report: Sensorimotor gating in idiopathic autism and autism associated with fragile $\mathrm{X}$ syndrome. Journal of Autism and Developmental Disorders. 2011; 41(2):24853. [DOI:10.1007/s10803-010-1040-9] [PMID] [PMCID]

[14] Lubans DR, Morgan PJ, Cliff DP, Barnett LM, Okely AD. Fundamental movement skills in children and adolescents: Review of associated health benefits. Sports Medicine. 2010; 40(12):101935. [DOI:10.2165/11536850-000000000-00000] [PMID]

[15] Schaaf RC, Miller LJ. Occupational therapy using a sensory integrative approach for children with developmental disabilities. Mental Retardation and Developmental Disabilities Research Reviews. 2005; 11(2):143-8. [DOI:10.1002/ mrdd.20067] [PMID]

[16] Hallahan D, Kauffman J, Pullen P. Published by pearson education, incexceptional learners: An introduction to special education. London: Pearson; 2015.

[17] Karami S, Sheikh M, Jamshidi A. [The affection of a period of selected exercising program on improving manipulative skills in children with developmental Coordination Disorder (CDC) (Persian)]. Motor Behavior. 2015; 6(18):15-30

[18] Bremer E, Balogh R, Lloyd M. Effectiveness of a fundamental motor skill intervention for 4-year-old children with autism spectrum disorder: A pilot study. Autism. 2015; 19(8):980-91. [DOI:10.1177/1362361314557548]

[19] Faal Moghanlo H, Hosseini F, Mikaili Manee F. [Effect of Spark motor program on the development of gross motor skills in intellectually disabled educable boys (Persian)]. Journal of Birjand University of Medical Sciences. 2013; 20(3):262-70.

[20] Nazarian Madvani A, Mokhtari Dinani M. [The effect of teaching on basic motor skills in boys' and girls' six years old of Tehran zone 9 and comparison with available norm (Persian)]. Journal of Physical Training Education. 2011; 1(1):51-9.

[21] Sarli A, Shahbazi M, Bagherzadeh F. [Investigate effectiveness of perceptual-motor tasks on visual and auditory attention of children with Attention Deficit Hyperactivity Disorder (Persian)]. Motor Behavior. 2014; 6(15):59-72.

[22] Afrooz G, Ghasemzadeh S, Taziki T, Mohajerani M, Dalvand $M$. [Effectiveness of sensorimotor interventions to increase the attention span of students with learning disabilities (Persian)]. Journal of Learning Disabilities. 2014; 4(1):23-37.

[23] Hartshorn K, Olds L, Field T, Delage J, Cullen C, Escalona A. Creative movement therapy benefits children with autism. Early Childhood Development and Care. 2011; 166(1):1-5. [DOI:10.1080/0300443011660101]

[24] Sadati A, Sazmand A, Mirzaee H, Karimlo M. [The study of gross motor activities on attention process in boy students with down syndrome (Persian)]. Archives of Rehabilitation. 2009; 10(3):31-7.

[25] Moon MS, Adelle R. Physical fitness and the mentally retarded: A critical review of the literature. The Journal of Special Education. 1982; 16(3):269-87. [DOI:10.1177/002246698201600304]

[26] Bouffard M. Movement problem solutions by educable mentally handicapped individuals. Adapted Physical Activity Quarterly. 1990; 7(2):183-97. [DOI:10.1123/apaq.7.2.183]

[27] Vuijk PJ, Hartman E, Scherder E, Visscher C. Motor performance of children with mild intellectual disability and borderline intellectual functioning. Journal of Intellectual Disability Research. 2010; 54(11):955-65. [DOI:10.1111/j.13652788.2010.01318.x] [PMID]

[28] Antonis K, Nickos A. Construct validity of the bruininksoseretsky test of motor proficiency-short form for a sample of Greek preschool and primary school children. Perceptual and Motor Skills. 2006; 102(1):65-72. [DOI:10.2466/pms.102.1.65-75]

[29] Gallahue D, Ozmun J. Understanding motor development. New York: McGraw-Hill Education; 2002. [PMID]

[30] Sadati Firoozabadi S, Abasi S. [The effectiveness of sensorimotor integration in improving motor skills in students with learning disabilities (Persian)]. Motor Behavior. 2017; 8(26):105-18. [DOI:10.22089/MBJ.2016.874]

[31] Shahbazi S, Rahmani M, Heyrani A. [Effects of sensorymotor integration activities in combination with feedback on balance in children with developmental coordination disorder (Persian)]. Journal of Exceptional Children. 2015; 63(5):97-110.

[32] Parhoon K, Parhoon H, Movallali G. Effectiveness of training sensory stimulation on gross motor skills of 5-7 years old children with Down Syndrome. International Journal of Academic Research in Psychology. 2014; 1(1):18-27. [DOI:10.6007/ IJARP/v1-i1/722]

[33] Sourtii H, Sazmand A H, Karbalaei Nouri A, Jadidi H. [Effect of sensory integration therapy on gross and fine motor skills of 5-7 years old children with Down Syndrome (Persian)]. Archives of Rehabilitation. 2008; 9(2):35-41.

[34] Ayres AJ, Robbins J. Sensory integration and the child: Understanding hidden sensory challenges. Beaverton: Western Psychological Services; 2005. 